\title{
(2) OPEN ACCESS \\ Social determinants of health and slippery slopes in assisted dying debates: lessons from Canada
}

\author{
Jocelyn Downie, ${ }^{1}$ Udo Schuklenk (i) ${ }^{2}$
}

\begin{abstract}
${ }^{1}$ School of Law, Dalhousie University Schulich School of Law, Halifax, Nova Scotia, Canada

${ }^{2}$ Department of Philosophy, Queen's University, Kingston, Ontario, Canada
\end{abstract}

\section{Correspondence to}

Dr Udo Schuklenk, Department of Philosophy, Queen's University, Kingston K7L 3N6, Ontario, Canada; udo.schuklenk@pm.me

Received 10 April 2021 Accepted 1 July 2021 Published Online First 4 August 2021

\section{SLinked}

- http://dx.doi.org/10.1136/ medethics-2021-107793

- http://dx.doi.org/10.1136/ medethics-2021-107794

- http://dx.doi.org/10.1136/ medethics-2021-107837

Check for updates

(c) Author(s) (or their employer(s)) 2021. Re-use permitted under CC BY-NC. No commercial re-use. See rights and permissions. Published by BMJ.

To cite: Downie J, Schuklenk U. J Med Ethics 2021;47:662-669.

\section{ABSTRACT}

The question of whether problems with the social determinants of health that might impact decisionmaking justify denying eligibility for assisted dying has recently come to the fore in debates about the legalisation of assisted dying. For example, it was central to critiques of the 2021 amendments made to Canada's assisted dying law. The question of whether changes to a country's assisted dying legislation lead to descents down slippery slopes has also come to the fore-as it does any time a jurisdiction changes its laws. We explore these two questions through the lens of Canada's experience both to inform Canada's ongoing discussions and because other countries will confront the same questions if they contemplate changing their assisted dying law. Canada's Medical Assistance in Dying (MAiD) law has evolved through a journey from the courts to Parliament, back to the courts, and then back to Parliament. Along this journey the eligibility criteria, the procedural safeguards, and the monitoring regime have changed. In this article, we focus on the eligibility criteria. First, we explain the evolution of the law and what the eligibility criteria were at the various stops along the way. We then explore the ethical justifications for Canada's new criteria by looking at two elements of the often-corrosive debate. First, we ask whether problems with the social determinants of health that might impact decision-making justify denying eligibility for assisted dying of decisionally capable people with mental illnesses and people with disabilities as their sole underlying medical conditions. Second, we ask whether Canada's journey supports slippery slope arguments against permitting assisted dying.

\section{INTRODUCTION}

The debate in medical ethics about assisted dying has by and large moved on from the question of whether assisted dying is in principle morally defensible to the specifics of when it is morally defensible. ${ }^{1}$ These specific issues include, but are not limited to, questions of scope (who should be eligible for an assisted death), and requests made in advance of loss of decision-making capacity. Indeed, not a year seems to go by without yet another country legalising or decriminalising assisted dying, yet not a day seems to go by without debates raging about these other issues.

These issues have led to many months of acrimonious academic as well as public debate in Canada. The core of the 2020-2021 debate was whether natural death on a sufficiently limited time horizon or predictable trajectory should be an eligibility criterion, or whether instead access to MAiD should also be available for decisionally capable people suffering, for instance, from irremediable severe mental illnesses or a range of diverse, severe disabilities. In the latter cases, death could well be many years, if not decades, away, and the trajectory and ultimate cause of death unpredictable. Many of the arguments are complex, and they have been rehearsed extensively during the debate in Canada since $2016 .{ }^{2}$ We do not intend to review those known arguments here again. Rather, we will focus on two arguments that got a new lease on life in the 2020-2021 round of MAiD debates.

The first is a 'social determinants of health' argument with respect to persons with disabilities and persons with a mental disorder as their sole underlying medical condition. Do problems with the social determinants of health that might impact decision-making justify denying eligibility for assisted dying for those individuals?

The second is a 'slippery slope' argument. Do changes to a country's assisted dying legislation lead to descents down slippery slopes?

We explore these two questions through the lens of Canada's experience both to inform Canada's ongoing discussions and because other countries will confront the same questions if they contemplate changing their assisted dying law.

Canada's MAiD law has evolved through a journey from the courts to Parliament, back to the courts, and then back to Parliament. Along this journey the eligibility criteria, the procedural safeguards, and the monitoring regime have changed. In this article, we focus on the eligibility criteria. First, we explain the evolution of the law and what the eligibility criteria were at the various stops along the way. We then explore the ethical justifications for Canada's new criteria by focusing on the social determinants of health and slippery slope arguments against the new criteria.

\section{CANADA'S LEGISLATIVE AND JUDICIAL JOURNEY}

In this section, we begin with an explanation of the first successful law reform effort and then describe the evolution of the law and our understanding of the law up to the 2021 amendments made to the Criminal Code of Canada. ${ }^{\mathrm{i}}$ ii We pay particular attention to the law as it relates to the ethical issues at the heart of this paper regarding the social determinants of health (specifically for persons with disabilities or mental illness) and slippery slopes.

${ }^{\mathrm{i}}$ There is also provincial legislation in Quebec (S.4, Bill 52, An Act Respecting End-of-Life Care, 1st Sess, 14th Leg, Quebec, 2013 (assented to 10 June 2014), RSQ c S32.0001, s 26) that predates the federal legislation but we limit the scope of this paper to federal MAiD law.

${ }^{\mathrm{ii}}$ Criminal Code, RSC 1985, c C-46. 
This legal overview is essential to ground an analysis of the ethical defensibility of the eligibility criteria in Canada's MAiD regime. Before one can engage with these two ethical critiques of the law, one must first understand what the law actually has been and is.

\section{Carter v. Canada (Attorney General) 2015 SCC 5}

The Criminal Code of Canada contained blanket prohibitions on aiding suicide (prohibited under its own, separate provision) and euthanasia (prohibited under the homicide provisions). These prohibitions were challenged in Carter v. Canada (Attorney General). In this case, several plaintiffs argued that the blanket prohibitions violated multiple rights protected under the Canadian Charter of Rights and Freedoms, specifically: (1) the right to life, liberty and security of the person and the right not to be deprived thereof except in accordance with the principles of fundamental justice (section 7); and (2) the right to equal protection and equal benefit of the law without discrimination (section 15). The Supreme Court of Canada agreed with the plaintiffs and declared:

Section 241 (b) and s. 14 of the Criminal Code unjustifiably infringe s. 7 of the Charter and are of no force or effect to the extent that they prohibit physician-assisted death for a competent adult person who (1) clearly consents to the termination of life and (2) has a grievous and irremediable medical condition (including an illness, disease or disability) that causes enduring suffering that is intolerable to the individual in the circumstances of his or her condition. ${ }^{\text {iii }}$ (para 147)

"Grievous and irremediable medical condition" was not defined by the Court. Irremediable, however, they noted, "does not require the patient to undertake treatments that are not acceptable to the individual." iii (para 127)

Justice Smith, at trial, conducted a robust analysis of the equality arguments for and against decriminalisation of assisted dying with respect to people with disabilities. She expressly considered expert evidence about the impact of ableism, the promotion of the idea that some lives are more valuable than others, the concern that clinicians will be more likely to agree to the assisted death of persons with disabilities than persons with cancer, the social construction of disability, and unconscious bias in the clinicians who would respond to requests. She concluded that "the law creates a distinction that is discriminatory. It perpetuates and worsens a disadvantage experienced by persons with disabilities. The dignity of choice should be afforded to Canadians equally, but the law as it stands does not do so with respect to this ultimately personal and fundamental choice."iv (para 1161)

\section{Canada (Attorney General) v. EF, 2016 ABCA 155}

The first court decision to offer insight into the meaning of the key eligibility criterion "grievous and irremediable medical condition" was Canada (Attorney General) v. EF.

This case involved a woman with a mental illness as her sole underlying medical condition (severe conversion disorder). ${ }^{\mathrm{v}}$ The

\footnotetext{
iii Carter v. Canada (Attorney General) 2015 SCC 5.

${ }^{\text {iv }}$ Carter v. Canada (Attorney General) 2012 BCSC 886.
}

v The case was in court because the SCC had suspended its declaration of invalidity of the Criminal Code provisions for 12 months to give Parliament time to amend the law should it want to do so. Parliament failed to meet this deadline and sought an extension. They were granted a 4 months extension but, in the meantime, individuals were permitted to go to court to seek a judicial authorisation to be permitted to access MAiD. They could get this authorisation if a court found that they met the criteria set out in the Carter decision. government argued that she did not meet the eligibility criteria from Carter, arguing that Carter was limited to those who are terminally ill and that individuals with a psychiatric illness were excluded from eligibility under Carter. However, the Alberta Court of Appeal disagreed:

In summary, the declaration of invalidity in Carter 2015 does not require that the applicant be terminally ill to qualify for the authorisation. ${ }^{\mathrm{vi}}$ (para 41)

Persons with a psychiatric illness are not explicitly or inferentially excluded if they fit the criteria (from the decision). ${ }^{\text {vi }}$ (para 59)

\section{A.B. v. Canada (Attorney General), 2017 ONSC 3759}

The second case to offer insight was A.B. v. Canada (Attorney General). This case involved an elderly woman with an advanced and incurable disease, suffering enduring and intolerable pain. Her natural death was not imminent (indeed, estimates were that she had ten years to live). ${ }^{\text {vii }}$ Justice Perell concluded that "natural death need not be imminent" viii (para 79) and "the physician need not opine about the specific length of time that the person requesting medical assistance in dying has remaining in his or her lifetime." viii (para 80)

Justice Perell's decision has frequently been relied on to support the interpretation of "natural death has become reasonably foreseeable" (in the 2016 law, discussed below) as "sufficient temporal proximity or on a predictable trajectory toward death." 34 This was then used to justify finding a person had met the reasonably foreseeable criterion even if they had, for example, a prognosis of many years or had just been diagnosed with ALS or Parkinson's.

At this point in Canada's journey, by virtue of court cases, it had become clear that some people with disabilities could be eligible for assisted dying as could some people with mental illness, even when the disability or mental illness was the person's sole underlying condition.

\section{Bill C-14 (2016)}

Some 16 months after the Carter decision was released, the Canadian Parliament passed Bill C-14 An Act to amend the Criminal Code and to make related amendments to other acts (medical assistance in dying). Most notably for the purposes of this paper, they included the requirement of a "grievous and irremediable medical condition" but defined it more narrowly than the SCC had done. Specifically, they defined it as follows:

A person has a grievous and irremediable medical condition only if they meet all of the following criteria:

- They have a serious and incurable illness, disease or disability;

- They are in an advanced state of irreversible decline in capability;

- That illness, disease or disability or that state of decline causes them enduring physical or psychological suffering

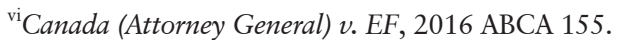

viicAB's current condition is that she is in an advanced state of incurable, irreversible, inflammatory and erosive osteoarthritis. Her medical condition is not imminently terminal. She is immobile due to constant arthritic pain and cannot perform daily tasks. Her pain is intense, despite every effort of her physicians to manage the pain, which she experiences in her knees, hips, back, stomach, fingers, and toes. She frequently wakes up screaming in pain. Her esophagus has constricted, and it is painful to eat and to swallow medication. She recently suffered from pneumonia. Her condition will worsen. There are no further treatment options. She feels that she has no future other than to live in pain until allowed to die.' [para 31]
}

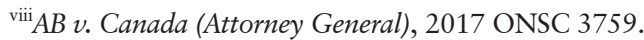


that is intolerable to them and that cannot be relieved under conditions that they consider acceptable; and

- Their natural death has become reasonably foreseeable, taking into account all of their medical circumstances, without a prognosis necessarily having been made as to the specific length of time that they have remaining. ${ }^{\text {ix }}$ (section $241.2(2))$

Even as Parliament was considering the Bill, constitutional law experts told the members of the House of Commons and the Senate that the definition of 'grievous and irremediable medical condition' was inconsistent with the SCC decision in Carter and, even more importantly, was not compliant with the Charter in that it violated the right to life, liberty, and security of the person as well as the equality provisions protecting against discrimination on the basis of disability. ${ }^{\mathrm{x}}$ Agreeing with these experts, the Senate amended the Bill to remove the requirement that a person's natural death have become reasonably foreseeable. ${ }^{5}$ However, the House rejected that amendment ${ }^{6}$ and the Senate backed down. ${ }^{\text {xi }}$ The Bill was passed with the full narrow definition. Ten days later, the bill was challenged in court in British Columbia, ${ }^{7}$ and subsequently also in Quebec. ${ }^{\text {xii }}$

\section{Truchon v. Attorney General (Canada) and Attorney General (Quebec) 2019 QCCS 3792}

The second Charter challenge launched against Bill C-14 got to court before the first (because of different rules of civil procedure in British Columbia vs Quebec) and was successful there. In this case, two individuals with severe disabilities argued that the eligibility criterion 'natural death has become reasonably foreseeable' violated their section 7 right to life, liberty, and security of the person and their 15 Charter right to equality before and under law and equal protection and benefit of law.

Justice Baudouin of the Quebec Superior Court agreed with the plaintiffs and declared that the reasonably foreseeable eligibility criterion violated the Charter in part because it discriminated against persons with disabilities (and others whose natural death was not reasonably foreseeable) to exclude them from access to assisted dying.

It is important to note that Justice Baudouin confirmed that individuals with mental illness were not excluded under Carter. ${ }^{\text {xii }}$ (para 483-492)

It is also worth noting here that the Attorney General of Canada chose not to appeal the Truchon decision. Explaining his decision, the Attorney General stated: "we decided not to appeal the Truchondecision because we agreed that medical assistance in dying should be available as a means to address intolerable suffering outside of the end-of-life context. To ensure the consistency of criminal law across the country, we committed to amending the Criminal Code". xiii Elsewhere, he noted that they decided not to appeal because they thought the decision was sound and that they would lose on appeal. ${ }^{\text {xiv }}$

\footnotetext{
${ }^{\mathrm{ix}}$ An Act to amend the Criminal Code and to make related amendments to other Acts (medical assistance in dying) Ch 3, First session, Forty-second Parliament, 17 June 2016.

${ }^{\mathrm{x}} \mathrm{See}$, for example, testimony of Joe Arvay before the Standing Senate Committee on Legal and Constitutional Affairs, Thursday, 5 May $2016 .{ }^{8}$

${ }^{x i}$ Friday, 17 June 2016, 1st Session, 42nd Parliament, Volume 150, Issue 52.

xii Truchon v. Attorney General (Canada) 2019 QCCS 3792.

xiii House of Commons Debates Friday, October 9, 2020 Edited Hansard Volume 150, No. 013, 2nd Session, 43rd Parliament.

${ }^{x i v}$ House of Commons Debates Tuesday, February 23, 2021 Edited Hansard Volume 150, No. 064, 2nd Session, 43rd Parliament.
}

C-7 (2021)

Some 17 months after the Truchon decision was released, the Canadian Parliament passed Bill C-7 An Act to amend the Criminal Code (medical assistance in dying). ${ }^{\mathrm{xv}}$ Most notably for the purposes of this paper, they removed 'natural death has become reasonably foreseeable' as an eligibility criterion for MAiD. ${ }^{\mathrm{xvi}}$ Therefore, all persons with disabilities are now allowed to access MAiD (assuming they meet the remaining eligibility criteria). The legislators also added an exclusion criterion: for the purposes of the 'serious and incurable illness, disease or disability' provision in the legislation, mental illness is not considered an 'illness, disease or disability', thus excluding persons with a mental illness as their sole underlying medical condition from eligibility for assisted dying (but only until March 2023, at which point this legal exclusion will be automatically repealed as the federal/provincial/territorial governments and professional regulatory bodies and professional associations will have had time to develop written protocols and procedural safeguards for MAiD for persons with a mental illness as their sole underlying medical condition). ${ }^{\text {xvii }}$

In some ways, Bill C-7 is closer to Carter than C-14 was: C-7 removed C-14's 'natural death has become reasonably foreseeable'. In other ways, Bill C-7 is further from Carter than C-14 was: C-7 added explicit full (although temporary) exclusion of mental illness as the sole underlying medical condition.

\section{IMPLICATIONS OF THE CURRENT DESTINATION}

At the end of the journey from Carter to Bill C-7, we have arrived at a position that has, among other things, the following implications for the ethical issues that will be discussed in the next part of this paper:

\section{Mental illness}

- Persons with mental illness as their sole underlying condition are not eligible for MAiD (but will be after 17 March 2023).

- Persons with mental illness can be eligible for MAiD—so long as they also have a physical condition that is a serious and incurable illness, disease or disability.

- Mental illness can be the cause of the person's enduring, intolerable, and irremediable suffering for which they are seeking MAiD—so long as their suffering from their mental illness is the cause of their advanced state of irreversible decline in capability (after 17 March 2023, their mental illness will be allowed to be the direct cause of the suffering).

- This is not an expansion of the Supreme Court of Canada decision in Carter. ${ }^{\text {xviii }}$

\section{Disabilities}

- Persons with disabilities that do not make their natural death reasonably foreseeable will now be eligible for MAiD.

\footnotetext{
${ }^{\mathrm{xv}}$ An Act to amend the Criminal Code (medical assistance in dying) Ch2, 2nd session, 43rd Parliament, March 17, 2021.

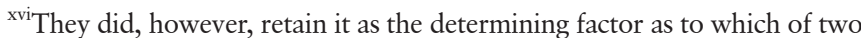
tracks of procedural safeguards a person must follow as they try to access MAiD.

${ }^{x v i i}$ This exclusion criterion has a sunset clause, meaning that it will be automatically repealed 2 years from the coming into force of the legislation.

${ }^{\text {xviii }}$ Some have argued for a narrower interpretation of the initial Carter criteria and therefore concluded that C-7 is an expansion of the Carter decision. See, for example, Attorney General of Canada and Attorney General of Quebec in Truchon. However, as explained in the text, this interpretation was rejected in both Canada (Attorney General) $v . E F$ and Truchon v. Canada (Attorney General) and the Attorney General chose not to appeal either of these decisions.
} 
- It is not only persons with disabilities who are now eligible as a result of the removal of the eligibility criterion of 'natural death has become reasonably foreseeable', but also people with chronic illnesses.

- This is not an expansion of the Supreme Court of Canada decision in Carter. .ix $^{\text {xix }}$

We turn now to the exploration of ethical arguments about the new eligibility criteria for MAiD in Canada-specifically the arguments relating to the social determinants of health and slippery slopes.

\section{SOCIAL DETERMINANTS OF HEALTH}

\section{Disability and the social determinants of health}

In the 2020-2021 debate over whether to remove Bill C-14's requirement that natural death be reasonably foreseeable, arguments based on the social determinants of health rose to particular prominence, ${ }^{\mathrm{xx}}$ mostly advanced by antiassisted dying disability rights groups. These arguments may be familiar to those who have followed these debates over the years, but they might be new to people unfamiliar with arguments grounded in frameworks like the "Vulnerable Persons Standard" ${ }^{12}$ or as made by groups like 'Not Dead Yet'. ${ }^{13}$

Before articulating these arguments, a point about representation and terminology is required. While many antiassisted dying disability rights activist groups have voiced these arguments, it is unclear to what extent these-often powerful-voices are representative of the views held by persons with disabilities writ large. In 2021, Dying with Dignity Canada, an assisted dying activist group, commissioned a survey of Canadians' views on proposed changes to Canada's assisted dying law. The survey showed no meaningful differences between Canadians identifying/not identifying as disabled in terms of their support for a permissive access regime. Sixty per cent of people with disabilities (and 69\% of all surveyed) wanted to remove the requirement that death be reasonably foreseeable. ${ }^{14}$ It is also worth emphasising that the plaintiffs in Lamb v. Canada (the British Columbia case) ${ }^{7}$ and Truchon v. Canada (the Quebec case) ${ }^{\mathrm{xii}}$ were people with disabilities as their sole underlying condition fighting for the removal of the reasonably foreseeable requirement. The survey we cite was commissioned by a proassisted dying advocacy group. However, we could find no other surveys. And of course, the plaintiffs are merely individuals; their existence and actions do not tell us about the views of other persons with disabilities. However, while we cannot claim that all persons with disabilities support removing reasonably foreseeable, we note that disability activist groups that oppose removing reasonably foreseeable do not speak for all persons with disabilities. Indeed, we cannot know

\footnotetext{
${ }^{\text {xix }}$ Some have argued for a narrower interpretation of the initial Carter criteria and therefore concluded that C-7 is an expansion of the Carter decision. See, for example, Attorney General of Canada and Attorney General of Quebec in Truchon. However, as explained by Justice Baudouin in Truchon [16: para 77-93], this narrower interpretation was rejected by the Federal External Panel on Options for a Legislative Response to Carter v. Canada, ${ }^{9}$ The Provincial-Territorial Expert Advisory Group on Physician-Assisted Dying, ${ }^{10}$ and the Special Joint Committee on PhysicianAssisted Dying. ${ }^{11}$

${ }^{\mathrm{xx}}$ It must be noted here that many of these arguments were made and rejected by the courts, most recently in Truchon. We go into them here because they have taken on such prominence in the public arena and are likely to play an outsize role in the coming debate that will take place under the auspices of an independent expert panel on the implementation of assisted dying for mental illness and the 5-year Parliamentary review of the legislation (with specific attention to be paid to mental illness and disabilities, among other things).
}

how many or what proportion they speak for. Therefore, rather than perpetuate the misperception that persons with disabilities are overwhelmingly (or even majority) opposed to assisted dying being available to persons with disabilities as their sole underlying medical condition by saying 'persons with disabilities arguments' or 'disability rights groups', we say 'anti-MAiD disability rights activist group arguments' and related variants.

Some antiassisted dying disability rights activists and scholars argue that what is often referred to as 'disability' should be seen as a variety of human existence, a mere difference that is unproblematic in its own right. ${ }^{15}$ Oftentimes the struggles of gay liberation activists are mentioned to drive home this point, with disabled, like gay, being said to be mere difference. ${ }^{16}$ The "mere difference' view could support the argument that it is never the disability itself that could render a person with disability's life not worth living, but rather it is the social determinants of health. On this view, it is the absence of reliable support services when they are needed, or poverty, homelessness, and so on, that reduce some or many persons with disabilities' quality of life to such an extent that they might ask for assisted dying. ${ }^{17}$

Empirical evidence supports the view that both disability as well as mental illness can reduce people's social determinants of health, resulting in a lower quality of life than would have otherwise been the case. For instance, for people who acquired disability later in life, the reported negative impacts on their social determinants of health oftentimes are a consequence of 'reduced inflow and increased outflow of finances [that] had subsequent negative effects on housing, transport and social interactions, and also personal relationships,' as one Australian study notes. ${ }^{18}$ A similar case has been argued for persons with intellectual disabilities, as reportedly they 'experience higher rates of common health conditions; poorer health outcomes; and restrictions to timely access to effective healthcare. Over a life course perspective, the cumulative effects of these inequalities compound over time, which essentially means that for people with intellectual disabilities such health inequalities begin earlier in their lives, and the cumulative effects have a greater impact on most as they get older. ${ }^{19}$ Based on evidence like this one could hold the view that in the absence of such negative impacts on a disabled person's social determinants of health, their disability might be a mere difference, but not a difference that would trigger requests for MAiD.

\section{Mental illness as sole underlying medical condition and the social determinants of health}

A similar pattern emerges with regard to decisionally capable people experiencing severe mental illnesses. Some commentators insist that people with mental illness as their sole underlying medical condition are seeking assisted dying because their suffering is caused, not by their condition, but rather by poverty, homelessness, racism and other social determinants of health. Other authors concede that the mental illness could cause the suffering but insist that the patient's suffering is remediable, and the treatments that could work are not available to the patient. On this argument, a person with mental illness asking for an assisted death is merely an indication of a healthcare system failing the needs of that patient. ${ }^{20}$

\section{Responses to the social determinants of health arguments (disability and mental illness)}

In many-if not all-jurisdictions, many people with disabilities as well as people with mental illnesses suffer from a disadvantage not inherent in their illness, and that is a decrease in their social determinants of health, which can manifest itself 
in a multitude of ways, including, but not limited to the lack of reliable access to social services and high-quality specialist healthcare. This under-resourcing of services is a long-festering scandal. There can be no question about the fact of suboptimal services, and one should not equivocate about it, neither should one equivocate about the obvious solution: significant increases of available healthcare and social services resources to assist such individuals. Indeed, advocates of the 2021 changes to Canada's assisted dying legislation called vigourously and repeatedly for such increases.

What can be questioned is what opponents of making these two classes of individuals eligible for assisted dying claim follows from this observation. They essentially hold the view that such patients should not be eligible for assisted dying, because their decision to ask for an assisted death might be a consequence, not of their direct illness-related suffering, but rather of these (in principle remediable) social determinants of health. They conclude that such patients should not be eligible for assisted dying until these resource shortcomings are fully remedied.

The Canadian Parliament and courts have considered the evidence and arguments with respect to social determinants of health in relation to the policy position on who should have access to MAiD. They have concluded that the evidence and arguments do not support prohibiting persons with disabilities as their sole underlying condition from accessing MAiD, and they only support restricting access to persons with mental illness as their sole underlying medical condition for 2 years. A critical conclusion to highlight here is that the Canadian Parliament and courts recognise the problems with the social determinants of health for many individuals with disabilities and mental illness, but are nonetheless committed to individual case-by-case assessments rather than group-based exclusions.

This is best expressed by Justice Baudoin in Truchon. She considered and addressed arguments grounded in concerns about social determinants of health, specifically, "lack of access to appropriate care; poverty; unemployment; ongoing abuse or violence" (note 263); "socioeconomic factors such as income, education, race, age, health insurance and institutionalization"xii (note 263); "poverty or financial precariousness"xii (note 298); "stigma and discrimination, poverty, low self-esteem, isolation, and inadequate resources"xii (note 433); and "lack of access to adequate medical resources and services"xii (note 323 ).

She concluded that:

[252] The Court cannot accept the concept of collective vulnerability suggested by the Attorney General because the broad protection that results therefrom is too general an application of a precautionary principle. Vulnerability (tied to various external factors including the social determinants of health) should not be understood or assessed on the basis of a person's belonging to a defined group, but rather on a case-by-case basis, at least for the purposes of an analysis under section 7 of the Charter. In other words, it is not the person's identification with a group characterized as vulnerable-such as persons with disabilities, Indigenous persons or veterans-that should bring about the need to protect a person who requests medical assistance in dying but, rather, that person's individual capacity to understand and consent in a free and informed manner to such a procedure, based on his or her specific characteristics.

[309] In the Court's view, however, we cannot, in the name of the principle of protecting certain persons from themselves or of socially affirming the inherent value of life, deny medical assistance in dying to an entire community of persons with disabilities precisely because of their disability. That is what the legislator is doing indirectly by providing wide-ranging protection of certain groups instead of implementing strict structural conditions to ensure that such persons are well protected, should it deem it appropriate. Again, collective vulnerability cannot be conceptually used as a basis to refuse medical assistance in dying.

[310] Mr. Truchon and Ms. Gladu, who belong to this category of persons, want to be given the choice to decide for themselves. The Court agrees with this. To do otherwise could lead to discrimination against persons with disabilities on the sole basis of their disability. These people are full citizens and consequently have the same rights as all other citizens, especially those that involve making decisions of utmost importance to their bodily integrity and dignity as human beings. Respect for their individual freedom that is expressed thoughtfully, freely and clearly also contributes to the affirmation of the inherent value of their lives.

Outside the halls of government and justice, additional arguments can be made against the social determinant of health arguments against allowing MAiD for persons with disabilities and mental illness as their sole underlying medical condition. Proponents of restrictive access regimes contribute, ironically, to the continuing stigmatisation of both disability as well as mental illness. They essentially advocate to remove such patients' agency, because they disapprove of the end-of-life choice that some of these patients would predictably make. The kind of strong paternalism-well intentioned as it may be-that is on display here must be placed where it belongs, in a long tradition of views of disability and of mental illness that renders such patients less able than others to make decisions about their own lives. Much of the sea change in societal views of both disability and mental illness is owed to successfully dispelling precisely such stigmatising myths. Opponents of patient choice when it comes to assisted dying and the eligibility of persons with disabilities and people with mental illness take this full circle. They sacrifice patient rights on the altar of their paternalistic values.

These arguments also fail to respect the lived experience of some people with disabilities or severe mental illness who insist that their suffering is caused by their condition, not by social determinants of health. ${ }^{21}$ They also fail to recognise that: some people with disabilities or severe mental illness seeking assisted dying are privileged and not lacking with respect to the social determinants of health; some people with disabilities or severe mental illness have good access to all possible treatments, supports, and services (and yet they have not helped them); and some decisionally capable persons with disabilities or severe mental illness reject the treatments, supports and services proposed by their clinicians (because they view life with them as worse than death). The arguments also fail to recognise that people seeking assisted dying often have comorbidities-both mental and non-mental illnesses. The social determinants of health arguments in relation to disabilities and severe mental illness can apply just as much where disability or severe mental illness is the sole underlying medical condition as a comorbidity. Unless one wants to argue that nobody with a disability or a severe mental illness should have access to assisted dying even for, for example, cancer and ALS, then the social determinants of health argument is not enough to justify excluding persons with a disability or a severe mental illness as their sole underlying medical condition.

The argument that people with disabilities or mental illness as their sole underlying medical condition should not have access to MAiD unless and until everyone has access to adequate supports and services has an historical antecedent, also rejected by both the Canadian Parliament and the courts-the argument that no one should have access to MAiD unless and until everyone can access palliative care in a timely fashion when they 
could benefit from it. ${ }^{22}$ The argument re: social determinants of health fails for the same reason the argument re: palliative care failed. As Justice Smith observed in Carter: "the argument that legalization should not be contemplated until palliative care is fully supported rests, as Dr. van Delden observed, on a form of hostage-taking. In other words, this argument suggests, the suffering of grievously-ill individuals who wish to die will serve as leverage for improving the provision of adequate palliative care." "iv (para 1274)

Furthermore, while none of the jurisdictions that have legalised or decriminalised assisted dying to date have made an answer to deficiencies in the availability of palliative care a precondition of the policy change, that does not mean that the resourcing of palliative care has not been improved in many places that have changed their laws toward a permissive assisted dying regime. Belgium deliberately and dramatically increased funding for palliative care when it legalised assisted dying, legislating that palliative care is a patient right in 2002.. ${ }^{23}$ Quebec included an explicit right to 'end of life care' (which includes palliative care in its definition) in its assisted dying legislation. ${ }^{x x i}$ Canada's government has dramatically increased investments into palliative care provision. ${ }^{24} 25$ But increasing access to palliative care was never a precondition of (rather than an initiative concurrent with or following) the policy change, and universal access to palliative care is not a standard that has been achieved in any of the permissive (or restrictive) jurisdictions in the world.

It is important at this juncture to recall what the moral basis of permitting assisted dying is: at its core, it is about respecting and supporting the self-regarding choices decisionally capable patients make when they suffer from a grievous and irremediable medical condition that causes their suffering to be intolerable.

It is possible, of course, that in some cases it is not just the disease-caused suffering that is resulting in a request for an assisted death. Undoubtedly, it is possible that the illnesstriggered harmful impacts on a person's social determinants of health could contribute towards rendering a patient's suffering intolerable.

However, even if one were to assume, for the sake of the argument, that the latter was the case, and it is a result of government neglect, and not merely a function of limited (healthcare) resources that cannot be overcome, it still would not follow that a patient who is unwilling to tolerate their situation any longer should be stripped of their agency to ask for an assisted death. Proponents of the view that such a patient's agency to make such decisions, and see them respected, should be removed, are seemingly ready to condemn such patients to potentially very long periods of excruciating suffering, in an attempt to improve a particular healthcare system as well as other contributors to those person's social determinants of health. Patients are reduced here to a means used to achieve another, worthy, objective. However, the decision to partake in such activism should only be by voluntary deliberate choice. It should not be a result of decisionally capable people being held hostage by strong paternalists.

A reply to this stance could note that that is unfair to ascribe such motives to those opposed to respecting patient choice, when really they're focused on keeping vulnerable patients alive until healthcare systems have improved to such an extent that fewer such patients (potentially none, if the 'mere difference'

${ }^{x x i}$ S.4, Bill 52, An Act Respecting End-of-Life Care, 1st Sess, 14th Leg, Quebec, 2013 (assented to 10 June 2014), RSQ c S32.0001, s 26. view is correct) would be motivated to ask for an assisted death. One would expect then, that only those patients whose suffering is caused by the disease itself, and not by social determinants of health that can be addressed, would request an assisted death. Our concern is that that policy stance would, in reality, translate into potentially permanently making such patients ineligible for an assisted death. Moreover, in keeping with what we have identified as the relevant moral values justifying the legalisation of assisted dying, it is clear that even the decision on whether or not to wait for such improvements is a choice decisionally capable patients are entitled to make themselves. We agree with Riddle that 'denying people with disabilities the right to exercise autonomy over their own life and death says powerfully damaging things about the disabled, their abilities, and their need to be protected. ${ }^{26}$

\section{SLIPPERY SLOPES}

Any changes to assisted dying eligibility criteria bring about slippery slope related claims and concerns. ${ }^{27}$ We have discussed the logical structure of slippery slopes and their questionable use in assisted dying arguments elsewhere. ${ }^{28}$ Here, we wish to address and refute the three slippery slope arguments that arose specifically in the context of the removal of the reasonably foreseeable criterion.

The first slippery slope argument argued that if reasonably foreseeable was removed, Canada would descend down a slippery slope to a place where persons with disabilities or mental illness would be coerced into MAiD. Proponents of this argument referred to the experiences in the other jurisdictions that were already permissive with respect to persons with disabilities and mental illness as the sole underlying condition (Netherlands and Belgium).

The proponents ignored the fact that Justice Smith had carefully considered the expert evidence re: slippery slopes in permissive jurisdictions. She concluded " $[t]$ his evidence serves to allay fears of the practical slippery slope. The evidence does not support the conclusion that, since the legalization of physicianassisted death, there has been a disproportionate impact, in either Oregon or the Netherlands, on socially vulnerable groups such as the elderly or persons with disabilities."iv (para 1241-2) In Carter, the Supreme Court of Canada subsequently noted: "The trial judge, after an exhaustive review of the evidence, rejected the argument that adoption of a regulatory regime would initiate a descent down a slippery slope into homicide. ${ }^{\text {’iii }}$ (para 120)

Even more significantly, proponents of this argument ignored the fact that Justice Baudouin, like Justice Smith before her, also considered the expert evidence offered in support of the slippery slope argument (this time about the Benelux countries and the US but also now about Canada). She concluded that there was no evidence of slippery slopes in permissive jurisdictions: "Neither the national data in Canada or Quebec nor the foreign data indicate any abuse, slippery slope or even heightened risks for vulnerable people when imminent end of life is not an eligibility criterion for medical assistance in dying." ${ }^{x i i}$ (para 466)

On this count then, it can be said that slippery slope based criticisms of the current legislation have merely claimed that a slippery slope exists, but evidence from other jurisdictions fails to demonstrate that it exists in reality. Furthermore, recent evidence from Canada runs counter to the slippery slope argument. A 2020 study of all MAiD-related deaths across Ontario between June 7, 2016 and October 31, 2018 revealed that 'recipients of MAiD were younger, had higher income, were substantially less likely to reside in an institution and were more 
likely to be married than decedents from the general population, suggesting that MAiD is unlikely to be driven by social or economic vulnerability. ${ }^{29}$ A 2021 study of older adults ( $>65$ years) who died under palliative care between June 1, 2016 and June 1, 2019 (50,096 of whom 920 received MAiD) concluded that 'medical assistance in dying was significantly less frequent for palliative care patients who had low rather than high socioeconomic status are less likely to receive medical assistance in dying under universal health insurance. ${ }^{30}$

A second type of slippery slope argument claims that Canada has moved from eligibility requiring that a person's natural death be reasonably foreseeable, to not requiring that-so Canada has landed further down a slope and is therefore a cautionary slippery slope tale. However, as already noted, not every change in eligibility criteria reveals slippage down a slope. It is acontextual to claim that Canada's legislative change is evidence of a slippery slope. To do so is to take a snapshot that obscures the entire scene. Yes, the change from C-14 to C-7 moves Canada in a more permissive direction. However, that ignores where Canada was before. The change from Carter to C-14 moved Canada in a more restrictive direction. The entire scene is that Canada has not become more permissive as between the Supreme Court of Canada decision in Carter and Bill C-7. Rather, there was a period during which Canada had an unconstitutional tightening of the eligibility criteria. Canada is simply back where the Supreme Court of Canada put it through Carter.

A final slippery slope argument that has been raised in this context takes another different form. It claims that once reasonably foreseeable is removed, there is no conceptual reason to limit assisted dying only to people who consider their suffering to be intolerable due to their, for instance, chronic disease condition. The slippery slope concern here is this: logically, what would stop us, in a next step, from making assisted dying available to someone who might find themselves in abject poverty, and who might decide to ask for an assisted death. They might consider their suffering to be intolerable due to their poverty. What this argument fails to recognise is that the removal of reasonably foreseeable did not change the eligibility criterion re: the cause of suffering. When reasonably foreseeable was in the law, the person's suffering had to be caused by a serious and incurable illness, disease or disability, and the person had to be in an advanced state of irreversible decline in capability, and their suffering had to be caused by the illness, disease or disability or state of decline. The same holds true now. This slippery slope argument might have legs if the earlier law required that a person's suffering had to be caused by a condition that made their natural death reasonably foreseeable, and then the new law expanded access to MAiD to people whose suffering is due to a chronic disease condition. But that is not what happened.

\section{CONCLUSION}

After years of legal action, as well as public, academic and Parliamentary review and debate, Canada has reached a permissive assisted dying regime that aligns the country's legislation closer to the eligibility criteria of the Supreme Court of Canada judgment that led to the legalisation of assisted dying than to the legislation that followed that judgment. Canadian courts have roundly rejected arguments against MAiD grounded in concerns about social determinants of health and slippery slopes.

Our ethical analysis of social determinants of health arguments opposed to permissive regimes, of the kind Canada implemented in 2021, demonstrates that they fail to justify excluding decisionally capable patients suffering non-terminal illnesses from assisted dying.

Our ethical analysis also demonstrates that the slippery slope arguments that arose in the context of the Canadian legislative change fail to show that the country's policy changes constitute evidence of movement down a slippery slope or that they set up an inevitable future descent down a slope to an undesirable destination.

Contributors We have both contributed in equal part to this paper.

Funding The authors have not declared a specific grant for this research from any funding agency in the public, commercial or not-for-profit sectors.

Competing interests None declared.

Patient consent for publication Not required.

Provenance and peer review Not commissioned; externally peer reviewed.

Data availability statement All data relevant to the study are included in the article.

Open access This is an open access article distributed in accordance with the Creative Commons Attribution Non Commercial (CC BY-NC 4.0) license, which permits others to distribute, remix, adapt, build upon this work non-commercially, and license their derivative works on different terms, provided the original work is properly cited, appropriate credit is given, any changes made indicated, and the use is non-commercial. See: http://creativecommons.org/licenses/by-nc/4.0/.

\section{ORCID iD}

Udo Schuklenk http://orcid.org/0000-0002-0061-4315

\section{REFERENCES}

1 Schuklenk U. New frontiers in end-of-life ethics (and policy): scope, advance directives and conscientious objection. Bioethics 2017;31(6):422-3.

2 Rooney W, Schuklenk U, van de Vathorst S. Are concerns about irremediableness, vulnerability, or competence sufficient to justify excluding all psychiatric patients from medical aid in dying? Health Care Anal 2018;26(4):326-43.

3 CPSNS. College of Physicians and Surgeons of Nova Scotia professional standard regarding medical assistance in dying, 2018. Available: https://cpsns.ns.ca/wpcontent/uploads/2018/12/ProfessionalStandard_MedicalAssistancelnDying_Dec2018. pdf [Accessed 6 Jun 2021].

4 Downie J, Chandler J. Interpreting Canada's MAiD Legislation, Institute for Research in Public Policy, 2018. Available: https://on-irpp.org/217yQ6p [Accessed 06 Jun 2021].

5 Senate of Canada. Wednesday, June 8, 2016, 1st session, 42nd Parliament, volume 150, issue 45. Available: https://sencanada.ca/en/content/sen/chamber/421/debates/ 045db_2016-06-08-e [Accessed 06 Jun 2021].

6 Edited Hansard - 42 ${ }^{\text {nd }}$ Parliament 1st Session, Volume 148, Number 074, 2016. Available: https://www.ourcommons.ca/DocumentViewer/en/42-1/house/sitting-74/ hansard

77 Lamb v. Canada (Attorney General). Available: http://eol.law.dal.ca/wp-content/ uploads/2016/07/Lamb-v-Canada.pdf [Accessed 06 Jun 2021].

8 Senate of Canada. Available: https://sencanada.ca/en/Content/Sen/committee/421/ Icjc/52552-e [Accessed 06 Jun 2021].

9 Government of Canada, Department of Justice. 'Consultation on physician-assisted dying: summary of results and key findings', final report from the external panel on options for a legislative response to Carter v. Canada, 2015. Available: https://www. justice.gc.ca/eng/rp-pr/other-autre/pad-amm/index.html [Accessed 07 May 2021].

10 Final report from the provincial-territorial expert advisory group on physicianassisted dying (30 November 2015 Government of Canada, Ministry of Health) (co-chairs: Jennifer Gibson and Maureen Taylor). Available: https://novascotia.ca/dhw/ publications/Provincial-Territorial-Expert-Advisory-Group-on-Physician-Assisted-Dying. pdf [Accessed 07 May 2021].

11 Medical Assistance in Dying: a patient-centered approach', report from the Special Joint Committee on Physician-Assisted Dying (February 2016 Parliament of Canada, House of Commons and Senate) (Joint Chairs: Hon. Kelvin Kenneth Ogilvie and Robert Oliphant). Available: https://www.parl.ca/DocumentViewer/en/42-1/PDAM/report-1 [Accessed 07 May 2021].

12 Vulnerable persons standard, 2016. Available: http://www.vps-npv.ca/ [Accessed 08 Sep 2016].

13 Not dead yet | the resistance. Available: https://notdeadyet.org/ [Accessed 25 Mar 2021].

14 IPSOS. Support for medically-assisted dying in Canada. slide 9 Présentation PowerPoint (d3n8a8pro7vhmx.cloudfront.net), 2021 [Accessed 24 Mar 2021].

15 Bognar G. Is disability mere difference? J Med Ethics 2016;42(1):46-9.

16 Asch A. Prenatal diagnosis and selective abortion: a challenge to practice and policy. Am J Public Health 1999;89(11):1649-57.

17 National Council on Disability. The danger of assisted suicide laws.. Available: https:// ncd.gov/sites/default/files/NCD_Assisted_Suicide_Report_508.pdf [Accessed 24 Mar 2021].

18 Frier A, Barnett F, Devine S, et al. Understanding disability and the 'social determinants of health': how does disability affect peoples' social determinants of health? Disabil Rehabil 2018;40(5):538-47.

19 McCausland D, McCallion P, McCarron M, et al. Health and wellness among persons ageing with intellectual disability. In: Bigby C, ed. Handbook on ageing with disability. New York: Routledge, 2021. 
20 Canadian Psychiatric Association (CPA). Medical assistance in dying (MAID): results of member consultation 2020. Ottawa (ON): CPA, 2021. https://www.cpa-apc.org/wpcontent/uploads/2020-CPA-MAiD-Consultation-Report-EN.pdf

21 Engelhart K. Should the right to die extend to people with mental illness? The Walrus, 2021. Available: https://thewalrus.ca/should-the-right-to-die-extend-to-people-withmental-illness/ [Accessed 21 Mar 2021].

22 De Lima L, Woodruff R, Pettus K, et al. International association for hospice and palliative care position statement: euthanasia and physician-assisted suicide. J Palliat Med 2017;20(1):8-14.

23 Dierickx S, Deliens L, Cohen J, et al. Involvement of palliative care in euthanasia practice in a context of legalized euthanasia: a population-based mortality followback study. Palliat Med 2018;32(1):114-22.

24 Government of Canada. Medical assistance in dying. Available: https://www.canada. ca/en/health-canada/services/medical-assistance-dying.html [Accessed 25 Mar 2021].
25 Parliamentary Budget Office, "Federal investments in palliative care", 2020. Available: https://www.pbo-dpb.gc.ca/en/blog/news/BLOG-2021-007-federal-investments-inpalliative-care-investissements-gouvernement-federal-dans-soins-palliatifs [Accessed 06 Jun 2021].

26 Riddle CA. Assisted Dying \& Disability. Bioethics 2017;31(6):484-9.

27 Steinbock B. Physician-assisted death and severe, treatment-resistant depression. Hastings Cent Rep 2017:47(5):30-42.

28 Schüklenk U, van Delden JJM, Downie J, et al. End-of-life decision-making in Canada: the report by the Royal Society of Canada expert panel on end-of-life decisionmaking. Bioethics 2011:25 Suppl 1(S1):1-73.

29 Downar J, Fowler RA, Halko R, et al. Early experience with medical assistance in dying in Ontario, Canada: a cohort study. CMAJ 2020;192(8):E173-81.

30 Redelmeier DA, Ng K, Thiruchelvam D, et al. Association of socioeconomic status with medical assistance in dying: a case-control analysis. BMJ Open 2021;11(5):e043547. 